\title{
Expression, tandem repeat copy number variation and stability of four macrosatellite arrays in the human genome
}

\author{
Deanna C Tremblay ${ }^{1}$, Graham Alexander $\mathrm{Jr}^{2}$, Shawn Moseley ${ }^{1}$, Brian P Chadwick ${ }^{1 *}$
}

\begin{abstract}
Background: Macrosatellites are some of the largest variable number tandem repeats in the human genome, but what role these unusual sequences perform is unknown. Their importance to human health is clearly demonstrated by the $4 \mathrm{q} 35$ macrosatellite D4Z4 that is associated with the onset of the muscle degenerative disease facioscapulohumeral muscular dystrophy. Nevertheless, many other macrosatellite arrays in the human genome remain poorly characterized.

Results: Here we describe the organization, tandem repeat copy number variation, transmission stability and expression of four macrosatellite arrays in the human genome: the TAF11-Like array located on chromosomes 5p15.1, the SST1 arrays on 4q28.3 and 19q13.12, the PRR20 array located on chromosome 13q21.1, and the ZAV array at 9q32. All are polymorphic macrosatellite arrays that at least for TAF11-Like and SST1 show evidence of meiotic instability. With the exception of the SST1 array that is ubiquitously expressed, all are expressed at high levels in the testis and to a lesser extent in the brain.
\end{abstract}

Conclusions: Our results extend the number of characterized macrosatellite arrays in the human genome and provide the foundation for formulation of hypotheses to begin assessing their functional role in the human genome.

\section{Background}

More than half of the human genome is composed of repetitive DNA [1], a proportion of which are tandem repeats. Tandem repeats are characterized by a given DNA sequence being repeated immediately adjacent to and in the same orientation as the first. In almost all cases the number of repeat units at a given locus vary between individuals and as such they are more commonly known as variable number tandem repeats (VNTRs).

Macrosatellites are among the largest VNTRs in the human genome [2] and are characterized by individual repeat units of several kilobases $(\mathrm{kb})$ and tend to be specific to a location on one or two chromosomes. Among the human macrosatellites, the best characterized are RS447, an array of 20-103 $4.7 \mathrm{~kb}$ tandem repeat units on 4 p16.1 along with a few copies at 8p23 [3], D4Z4 on

\footnotetext{
* Correspondence: chadwick@bio.fsu.edu

'Department of Biological Sciences, Florida State University, King Life Science Building, Tallahassee, FL 32306-4295, USA

Full list of author information is available at the end of the article
}

$4 \mathrm{q} 35$ and $10 \mathrm{q} 26$, an array of as few as 1 to over 1003.3 $\mathrm{kb}$ tandem repeat units $[4,5]$ and DXZ4, an array of 50100 copies of a 3-kb repeat unit specifically located at Xq23-24 [6]. The role of some tandem repeat DNA is more obvious due to their location, such as the extensive alpha satellite tandem repeats that define human centromeres [7] or the tandem repeat DNA at human telomeres [8]. What function macrosatellites have in genome biology is unclear. However, reduction in the size of D4Z4 on $4 \mathrm{q} 35$ to fewer than 10 tandem repeat units is associated with onset of the third most common inherited form of muscular dystrophy, facioscapulohumeral muscular dystrophy (FSHD) [5]. Numerous models have been proposed to explain how D4Z4 contraction could result in FSHD [9]. One early model suggested that reduction in the size of D4Z4 packaged as heterochromatin could result in a position-effect on adjacent gene expression [10]. Results from several studies testing this model are mixed, with some showing support [11-14], and others not [15-19]. More recently focus has 
turned to expression of the array itself. Like RS447, that contains an open reading frame (ORF) in each monomer that codes for a novel deubiquitinating enzyme [20], an ORF is present in D4Z4 monomers that encodes double homeobox 4 (DUX4) [10], a DNA binding protein [21] that alters expression levels of myogenic regulators in myoblasts [22]. DUX4 expression can be detected in patient myoblasts [21] but not control individuals. Recent evidence suggests that detectable levels of DUX4 in patients is due to polyadenylation and stabilization of transcripts originating from the most distal monomer in the array due to a polyadenylation signal located immediately distal to the array [23], a feature that is found only on chromosomes with the FSHD pathogenic 4qA161 haplotype [24].

The X-linked macrosatellite DXZ4 is also expressed [25] and contains several short ORFs [6], but none show any homology to known proteins. Unlike RS447 and $\mathrm{D} 4 \mathrm{Z} 4$, the location of DXZ4 on the X chromosome means that in females it is exposed to the mammalian dosage compensation process $\mathrm{X}$ chromosome inactivation (XCI). XCI repackages the chosen inactive $\mathrm{X}$ chromosome (Xi) into facultative heterochromatin [26]. Somewhat counter intuitively, DXZ4 adopts a more euchromatic conformation on the Xi while the surrounding chromosome is packaged into heterochromatin, whereas on the active X chromosome (Xa) DXZ4 is packaged into heterochromatin surrounded by euchromatin $[25,27]$. The euchromatic Xi form of DXZ4 is bound by the epigenetic organizer protein CTCF [28] suggesting that on the Xi, DXZ4 is performing a different function than on the Xa. Intriguingly, contracted D4Z4 arrays in FSHD adopt a chromatin configuration similar to DXZ4 on the Xi [29] including the binding of CTCF [30] that likely contributes to the disease permissive state.

These data suggest that tandem repeat copy number, chromatin organization and expression are important features of macrosatellites, and provide some insight into functional attributes of these sequence, in particular the impact of short arrays in FSHD. Indeed, in Saccharomyces cerevisiae, retention of large rDNA tandem repeats are necessary for sister chromatid cohesion and maintenance of genome integrity [31]. Therefore exploring macrosatellite VNTR and organization in the human genome is a high priority. In the current manuscript we describe the organization, expression, tandem repeat copy number polymorphism and stability of four macrosatellite arrays in the human genome.

\section{Results}

Characterization of the TAF11-Like macrosatellite array on chromosome $5 \mathrm{p} 15$

In order to identify novel human macrosatellite arrays, the UCSC genome browser http://genome.ucsc.edu/ was used with the segmental duplication annotation activated to explore by eye the complete human genome sequence (NCBI36/hg18). The segmental duplication track identifies duplications of $1 \mathrm{~kb}$ or greater that share $90 \%$ or more DNA sequence identity [32]. Regions annotated as segmental duplications that originate from the same chromosomal interval and displayed a regular repeat masking pattern were selected for further examination. These rough criteria were chosen based on the fact that the well characterized macrosatellite arrays DXZ4, D4Z4 and RS447 were clearly identified using the same parameters.

One tandem array that spans $\sim 143 \mathrm{~kb}$ (Chr5: $17,543,001-17,686,000$ of hg18) was identified on the short arm of human chromosome 5 at 5 p15.1. The closest annotated gene to the $5 \mathrm{p} 15.1$ macrosatellite repeat is BASP1 (Brain Abundant, membrane attached Signal Protein) located approximately $210 \mathrm{~kb}$ distal to the array (Figure 1A). On the proximal side, the nearest annotated gene $\mathrm{CDH} 18$ ( $\mathrm{CaDHerin} 18$ type 2 preproprotein) is located over $1.8 \mathrm{Mb}$ away. A cluster of expressed sequence tags (ESTs) represented by BC028204 (UniGene cluster Hs.407197) resides approximately $160 \mathrm{~kb}$ proximal to the array with some EST members as close as $30 \mathrm{~kb}$.

An individual repeat unit of the array is approximately $3.4 \mathrm{~kb}$ and is defined by a BglII restriction enzyme recognition site that cuts once per monomer (Figure 1A). Monomers within the contiguous array share between 99.3-99.7\% nucleotide identity based on BLAT alignment results http://genome.ucsc.edu using monomers from genome build hg18, with most variation due to single nucleotide polymorphisms (SNPs) between monomers. The base composition of each monomer is approximately $49.6 \% \mathrm{GC}$ and a little under a third $(31.7 \%)$ of each monomer is repeat masked due to a combination of a retrotransposon LTR (MLT1E3), partial Alu repeat (AluSx) and a disrupted DNA transposon (Charlie 2a). A short open reading frame (ORF) resides within each monomer spanning $594 \mathrm{bp}$, and encodes a predicted TATA binding protein associated factor 11 like protein (TAF11-Like). Three SNPs reside within the ORF in the different monomer sequences represented in the hg18 build. None introduce any frame shifts or premature stop codons and therefore maintain the reading frame of the ORF. One SNP is silent exchanging a glycine codon for another (within the ORF a T-C at nucleotide 24 changing a GGT to a GGC). The other two SNPs result in an amino acid change: a T-G at nucleotide 298 changing TCC to GCC and consequently a seriene to alanine (amino acid 99 within the ORF), and a A-G at nucleotide 581 changing a AAA to an AGA resulting in a lysine to arginine change (amino acid 194 in the ORF). 

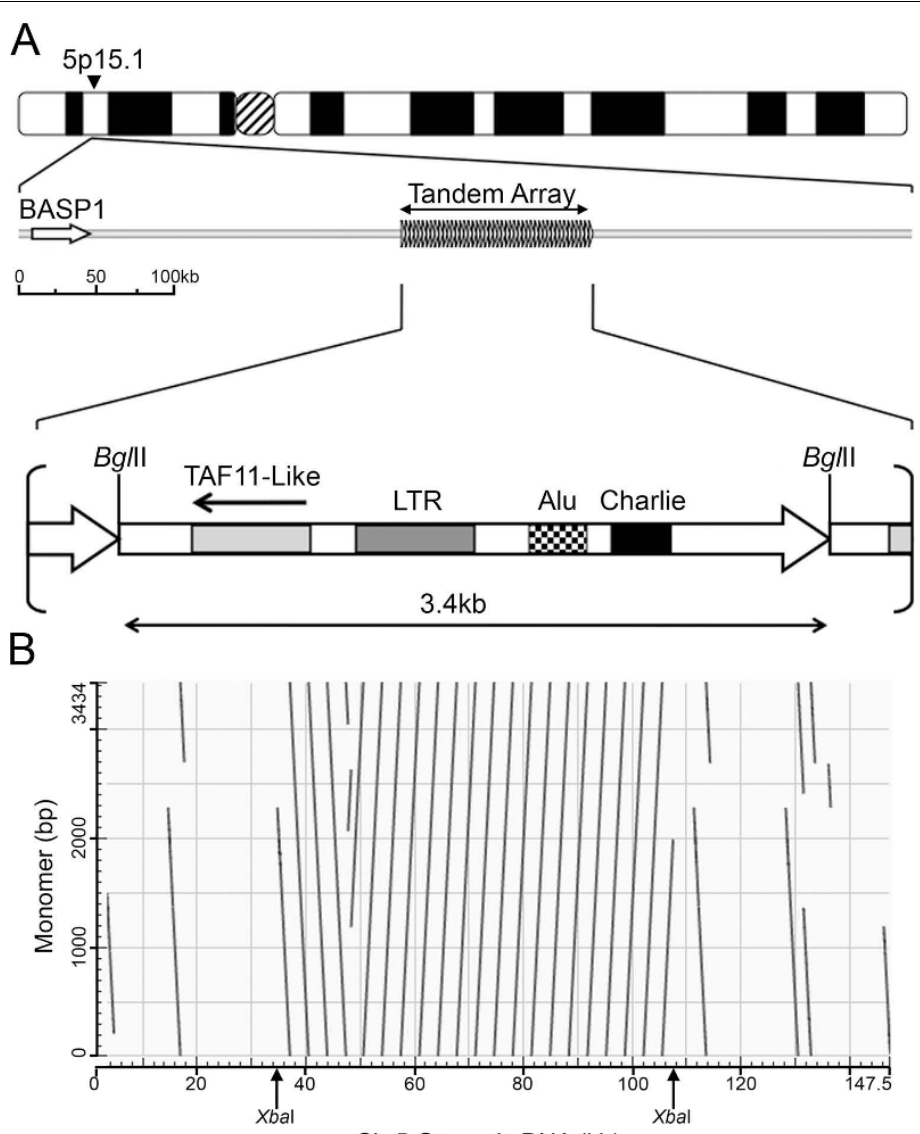

C

Chr5 Genomic DNA (kb)

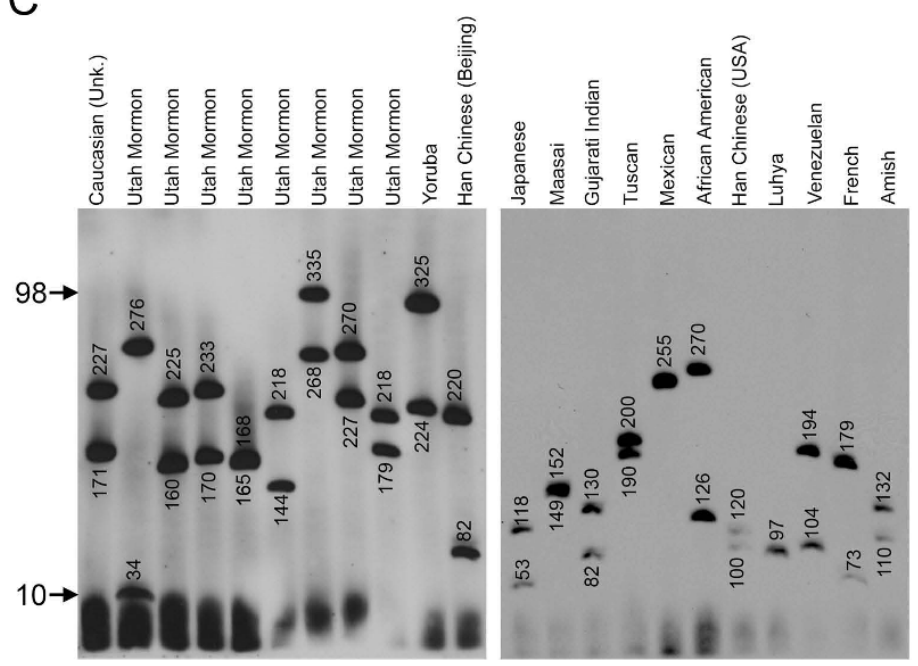

Figure 1 Characterization of the Chromosome 5p15.1 TAF11-Like macrosatellite array. (A) Ideogram of chromosome 5 and schematic map of the region surrounding the macrosatellite. Right facing arrow heads represent the array. BASP1 is indicated to the left. Scale indicates the approximate distances represented on the map in kb. Below the Array is a map of an individual $3.4 \mathrm{~kb}$ monomer (Large right facing arrow). Bglll restriction endonuclease sites that define a single monomer are indicated to the left and right. Repetitive elements LTR, Alu and Charlie are indicted by the shaded and patched boxes. The ORF for TAF11-Like is highlighted and orientation indicated by the left facing arrow. (B) Higherorder organization of the chromosome 5 array as revealed by dot-plot analysis. On the $y$-axis is a $3.4 \mathrm{~kb}$ monomer and on the $\mathrm{x}$-axis is the 147 $\mathrm{kb}$ genomic interval (17.5 Mb according to build hg18). Xbal restriction endonuclease sites that immediately flank the array that are used for the PFGE are indicated. Dot-plot generated using NCBI Blast, and output image labelled in Adobe Photoshop CS2. (C) Copy number variation of the chromosome 5 macrosatellite array. Southern blot of Xbal cut DNA from 22 unrelated individuals separated by pulsed field gel electrophoresis and hybridized with a chromosome 5 macrosatellite probe. The ethnicity of the individuals is indicated at the top. The size of the hybridizing fragments in $\mathrm{kb}$ are indicated on the blot. Arrows to the left indicate the range in size of the array as inferred copy number. 
A comparison of the ORF nucleotide sequence against entries in the nucleotide collection database using BLAST http://blast.ncbi.nlm.nih.gov/Blast.cgi identified a conserved sequence in primates. Translation of these sequences (Figure 2) reveals a conserved ORF of 198 amino acids in great apes (90.9-96.0\% identity) and 199 amino acids in Macaque (86.4\% identity). Of note, amino acid 99 in the human ORF that is either an alanine or seriene based on the SNPs described above is an alanine in all the primates examined. Likewise, the SNP that results in either an arginine or lysine at amino acid 194 is a lysine in the great apes, but a glycine in Macaque. However, until greater sequence coverage of the TAF11-like array is achieved in all primates, the significance of these coding SNPs cannot be readily assessed at this time. A comparison of the TAF11-Like nucleotide sequence against the genomes of each primate revealed for all a tandem array located within a region of synteny to human $5 \mathrm{p} 15$ that is in the vicinity of $B A S P 1$, and therefore likely identifying the orthologous primate macrosatellite arrays.

Copy number variation, meiotic and mitotic instability of the TAF11-Like macrosatellite array

Assembly of large tandem repeat DNA sequence is problematic for in silico assembly, in particular the challenge of whether to align two identical sequences as the same or separate given that in vivo they may actually be immediately adjacent to one another. According to the current DNA assembly, the array is largely composed of 17 monomers arranged in tandem, with 3 complete monomers inverted at the distal edge relative to the main array. Fragments of monomers can also be found several $\mathrm{kb}$ away from the immediate edges of the array (Figure 1B). To investigate the copy number variation of the TAF11-Like array, genomic DNA from 22 unrelated individuals was embedded in agarose plugs and subjected to digestion with $\mathrm{XbaI}$ which does not have any recognition sites within any complete monomers, but is predicted to cut immediately flanking the main array (Figure 1B). The DNA fragments were separated by pulsed field gel electrophoresis (PFGE) and Southern blotted DNA hybridized with a probe specific to the array (Table 1). The size of the hybridizing bands ranged from $34 \mathrm{~kb}$ to $335 \mathrm{~kb}$ indicating that the size of the TAF11-Like array is very polymorphic in the general population (Figure 1C). Because an individual monomer is approximately $3.4 \mathrm{~kb}$, these data would indicate that as few as 10 and as many as 98 tandem copies of a monomer can be present at an array, a range comparable to that seen for the chromosome 4 macrosatellite array D4Z4.

Given the polymorphic nature of the TAF11-Like array, we investigated the stability of the array through meiosis and mitosis by monitoring Mendelian inheritance of alleles of the array through three generations in three independent CEPH families (Figure 3). Whereas most individuals inherited arrays that were the same

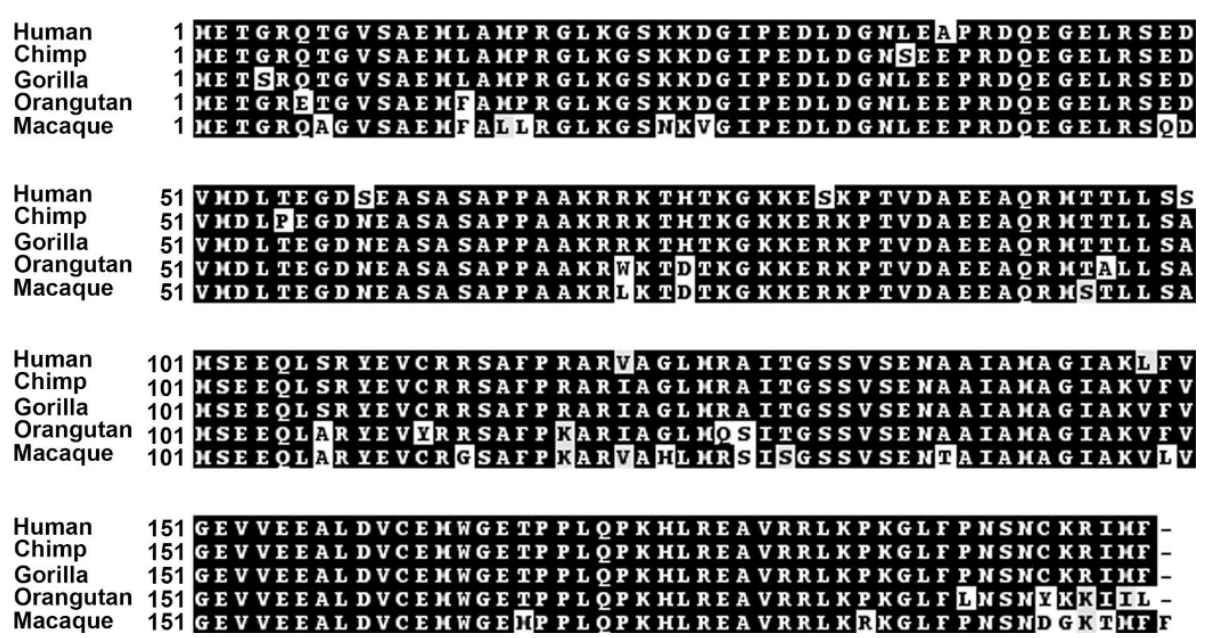

Figure 2 Conservation of TAF11-Like protein in primates. Alignment of the predicted amino-acid sequence of the TAF11-Like protein from great apes and macaque. The primate is listed to the left, as is the amino-acid residue number. Identical amino-acids are highlighted in black, amino-acids with similar properties are black letters shaded grey and divergent residues are black letters on a white background. Alignments were prepared using ClustalW2 http://www.ebi.ac.uk/Tools/clustalw2/index.html and the output used to generate the shaded version shown using the Boxshade 3.21 server http://www.ch.embnet.org/software/BOX_form.html. Chimp sequence obtained from Pan troglodytes, complete BAC clone containing 20 copies of TAF11-Like (Accession number AC182494). Gorilla sequence obtained from Gorilla gorilla genome assembly gorGor3. Orangutan sequence obtained from Pongo pygmaeus genome assembly PPYG2. Macaque sequence obtained from Macaca mulatta sequence (Accession number NC_007863). 
Table 1 Macrosatellite primers

\begin{tabular}{lllll}
\hline Target & Application & Forward & Reverse & Size \\
\hline Chr5 & Probe & ACTCGTGACGAACCGACTTG & GCTTGTAGGCTTATGTCTGG & 571 bp \\
Chr5 & Probe & TGATTCCTCCAGCTGGAAAG & CAGCAAGAAGGATGGAATCC & 789 bp \\
Chr13 & Probe & GGAAATCACGGAGACCGCAG & GTTCCATTCCAATCGCCTTG & 472 bp \\
Chr4/19 & Probe & GGAGGGTGGTTCTTGCAG & AGACGTTGAGCAGACTAAG & 576 bp \\
Chr9 & Probe & GGGCAAATTCGAGTGAAGG & CCAGTTCCAGCGGTATTC & 779 bp \\
Chr5 & RT-PCR & CAGGGTGTCATCCTCTGAG & CAGCAAGAAGGATGGATCC & 226 bp \\
Chr13 & RT-PCR & GGAAATCACGGAGACCGCAG & ACAACGTGGTGGCAGATAG & 306 bp \\
Chr4/19 & RT-PCR & GGGTGGTTTCTTGCACGTC & CGGGGAGTCTTCTTGTGG & 594 bp \\
Chr9 & RT-PCR & TGGTGACGACTCGCGAGAG & CAAAGCACCGGCCTAGATCG & 154 bp \\
GAPDH & RT-PCR & GAAGGTGAAGGTCGGAGTC & AGGTCCACCACTGACACGTT & 729 bp \\
\hline
\end{tabular}

Primers used in the current study to amplify the macrosatellites listed for probe generation or assessment of expression by RT-PCR analysis.

size as those of their parents, one individual acquired an allele approximately two repeat units smaller than siblings inheriting the same allele (Figure 3B, 7026) suggesting meiotic instability. A second individual showed the appearance of a new smaller allele as well as retaining the parental allele (Figure 3A, 7030), indicative of somatic instability of the array. To rule out possible contamination of the 7030 cell line with cells from an unrelated individual, alleles of other macrosatellites were assessed on the same blot. In each case, 7030 alleles were consistent with the parents and no additional bands were detected (data not shown).

\section{Expression of the TAF11-Like array}

Given the conserved ORF (Figure 2) and similarity to TAF11, reverse transcription PCR (RT-PCR) was performed on a panel of complementary DNA (cDNA) prepared from total RNA isolated from 20 human tissues. Most tissues did not show evidence of TAF11-Like expression with the notable exception of testis, fetal brain and whole brain (Figure 4). Weaker signals could also be detected in fetal liver and prostate.

\section{Characterization of the chromosome 4 and 19 SST1 macrosatellites}

Along with the TAF11-Like array, a macrosatellite was identified on chromosome 4 and 19 (Figure 5). This array was previously reported as a moderately repetitive tandem array that was initially identified as a repetitive sequence with homology to adenovirus [33]. The repeat was named SST1 due to the restriction enzyme SstI cutting once per monomer generating a common $2.5 \mathrm{~kb}$ fragment on Southern hybridization. On chromosome 4 the SST1 array resides within a gene poor region of 4q28.3 with the nearest annotated flanking genes being PCDH10 1.4 Mb distal to the array and C4orf33 approximately $2.6 \mathrm{Mb}$ proximal. The array is composed of $2.4 \mathrm{~kb}$ monomers in tandem with one partial monomer inverted and $210 \mathrm{~kb}$ distal to the main array (Figure 5A). Each monomer is moderately GC rich (64\%) and contains a CpG island (CGI) of about $400 \mathrm{bp}$. With the exception of a few simple repeats accounting for less than $5 \%$ of a monomer, the remaining sequence does not contain any other repetitive elements. A comparison of the 2.4-kb sequence to entries in the public databases primarily indentifies other chromosome 4 monomers (97-100\% sequence identity) as well as monomers from the chromosome 19 arrays (92-93\% sequence identity). Other matches of $>90 \%$ over $1.8 \mathrm{~kb}$ were identified on chromosome 9 (4 matches) and 21 (single match). In the current DNA assembly, the chromosome 4 SST1 array is represented by 17 uninterrupted $2.4 \mathrm{~kb}$ monomers therefore covering approximately $40 \mathrm{~kb}$ (Figure 5B).

Chromosome 19 contains two SST1 arrays separated by approximately $1 \mathrm{Mb}$ with several partial monomers scattered either side of the more distal array (Figure 5C). Unlike the chromosome 4 array, on chromosome 19 the two SST1 macrosatellites are embedded within a gene rich region of $19 q 13.12$. Intriguingly, most of the genes encode members of the kruppel $\mathrm{C} 2 \mathrm{H} 2$-type zincfinger protein family with two genes proximal, sixteen between and eleven distal of the two SST1 macrosatellites. Monomers of the chromosome 19 SST1 arrays are slightly longer than those at chromosome 4 (2.5 kb v 2.4 $\mathrm{kb})$. Within the proximal or distal chromosome 19 array monomers share $>99 \%$ sequence identity compared to 97-98\% identity between the two arrays based on BLAT results using a single monomer from each array. The orientations of the two arrays are inverted relative to one another and are represented by 17 (proximal array) and 15 monomers (distal array) arranged in tandem (Figure 5D).

\section{Copy number variation and instability of the SST1 macrosatellite arrays}

To investigate copy number variation of monomers within the SST1 macrosatellite arrays, agarose embedded DNA from 22 unrelated individuals was digested with 


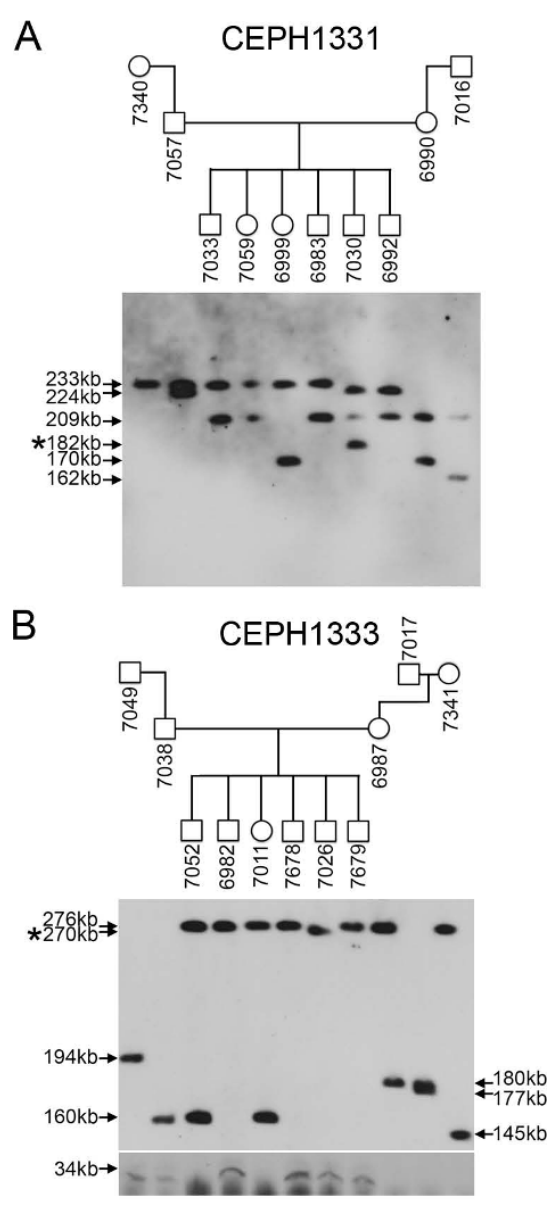

C
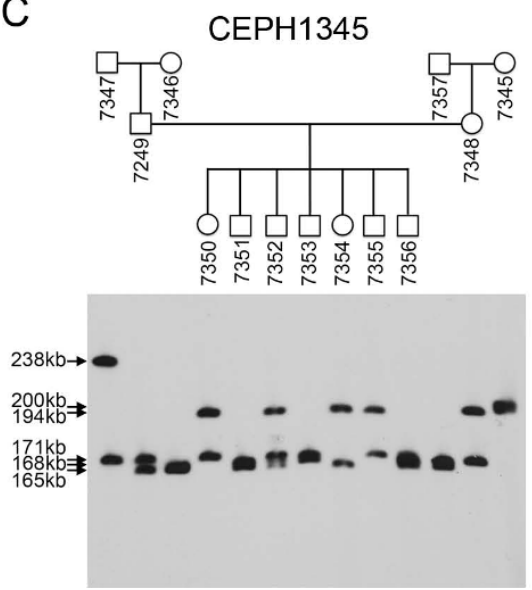

Figure 3 Unstable transmission of the chromosome 5 macrosatellite. Inheritance of the chromosome 5 macrosatellite through three generations in three CEPH Utah pedigrees. (A) CEPH1331, (B) CEPH-1333 and (C) CEPH-1345. Members of each family are indicated above each blot in the pedigrees and the numbers given are the Coriell GMO- ID for each member of the family. The size of the hybridizing fragments are given to the left and right sides of the blots. The blot in image (B) comes from two separate blots for which DNA was separated under different conditions to ensure resolution and visualization of the largest and smallest arrays. The asterisk indicate alleles of altered size.
$\mathrm{XbaI}$ that does not cut within the array and separated by PFGE before Southern blotting and hybridization with a probe specific to the SST1 arrays. Given the high sequence identity between the three arrays, the probe detected both chromosome 4 and 19 SST1 macrosatellites with most individuals showing all 6 alleles (Figure $5 \mathrm{E})$. Alleles ranged from as large as $387 \mathrm{~kb}$ to less than $35 \mathrm{~kb}$ indicating tandem arrays of between 14 to 154 monomers. In order to determine if large and small alleles are common to both chromosome 19 and/or chromosome 4 SST1 macrosatellite arrays, PFGE was performed on agarose embedded DNA digested with enzymes that specifically cut each monomer within the chromosome 4 array (ApaLI) or chromosome 19 arrays (PvuII) (Figure 5A and 5B). Specifically removing the chromosome 19 arrays with PvuII resulted in small alleles only, whereas most large alleles remained intact and comparable in size upon digestion with ApaLI that specifically removes the chromosome 4 arrays (Figure 5F). These data suggest that large SST1 arrays are more common on chromosome 19 than chromosome 4.

Given the large range of allele sizes for the SST1 arrays, we next investigated stability of transmission of alleles through three generations in two CEPH families (Figure 6). In one individual (Figure 6B, 6987), two new alleles of approximately $260 \mathrm{~kb}$ and $180 \mathrm{~kb}$ can be detected that are not present in either parent. The larger of the two alleles was stably transmitted through the germ line to three offspring, whereas the smaller allele was not detected.

\section{Expression of the SST1 array}

According to the UCSC genome browser, a cluster of ESTs match a monomer centered upon the CGI. Primers were designed to amplify across the CGI and were used to detect expression from the SST1 macrosatellite using cDNA prepared from 20 human tissues. Expression was readily detected in all tissues (Figure 4, second row). Several open reading frames exist within chromosome 4 and 19 monomers, but none match any known proteins in the public databases.

\section{Characterization of the PRR20 macrosatellite on chromosome 13}

A third candidate macrosatellite array was detected at chromosome 13q21.1. The array resides within a gene poor region with the nearest annotated gene $450 \mathrm{~kb}$ distal (PCDH17) and over $4 \mathrm{Mb}$ proximal (OLFM4) (Figure 7A). An individual tandem repeat unit is 6.6 $\mathrm{kb}$, is approximately $50 \% \mathrm{GC}$ and $43 \%$ repeat masked for LINE, Alu and a simple repeat. Two CGIs reside within a single monomer covering $333 \mathrm{bp}$ and $201 \mathrm{bp}$. Each monomer contains the proline-rich-20 gene (PRR20). The gene is composed of three exons of 214 


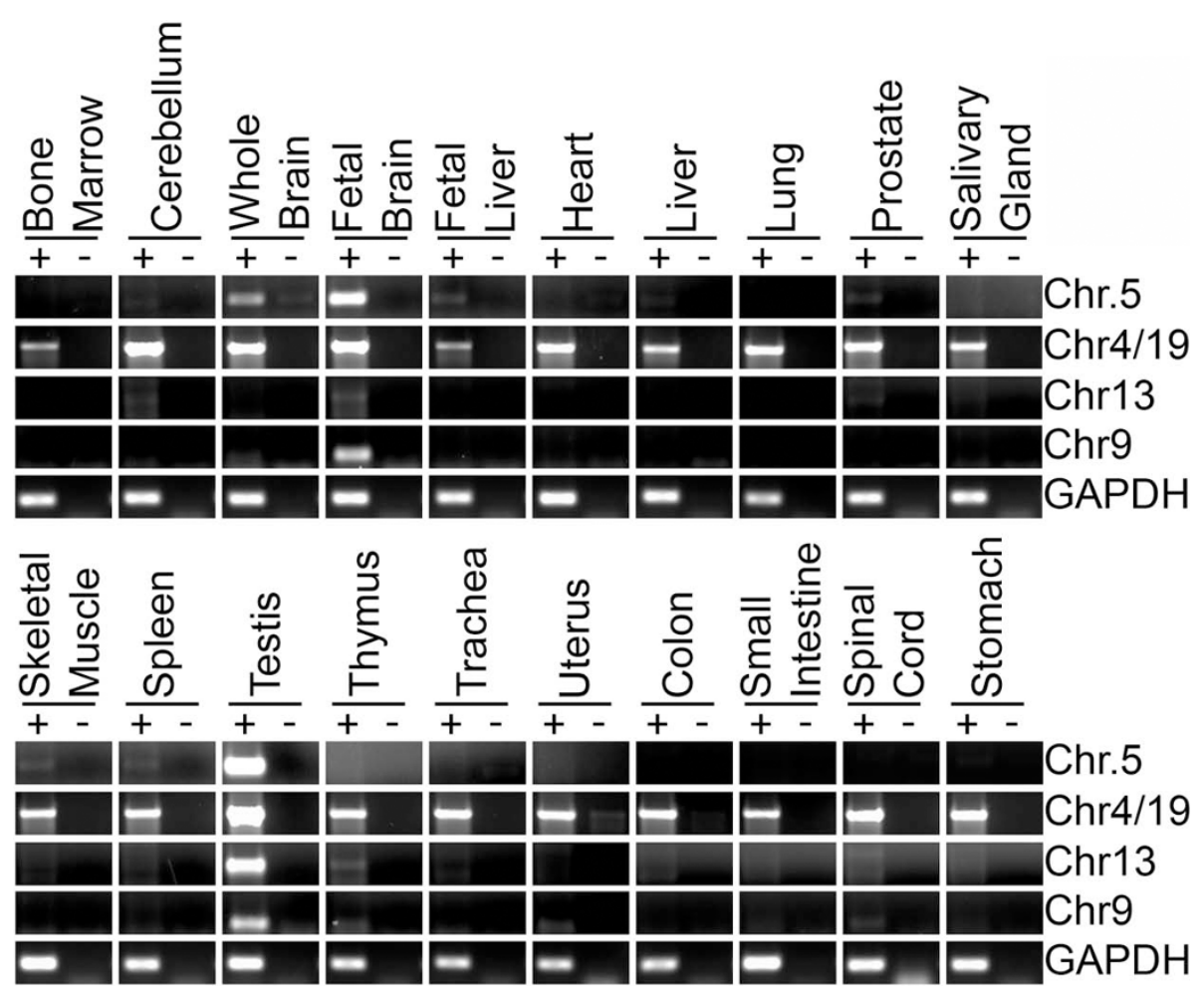

Figure 4 Expression profile of macrosatellite arrays. RT-PCR analysis of the macrosatellite arrays listed to the right in a panel of cDNA form 20 different human tissues. The tissues are listed above each agarose gel image with " + " indicating cDNA with reverse transcriptase and "-" indicating the no reverse transcriptase control. Details regarding the size of product and sequences of primers used are given in Table 1.

bp, $71 \mathrm{bp}$ and $1562 \mathrm{bp}$ and encodes a 221 amino acid proline rich protein. RT-PCR analysis indicates that PRR20 is primarily expressed in the testis with low levels of transcript detected in cerebellum, fetal brain, prostate and thymus (Figure $4,3^{\text {rd }}$ row). Orthologous copies of PRR2O were identified in great apes and Macaca mulatta that encode PRR20 proteins that have $95-71 \%$ amino acid identity (chimp to macaque) with human PRR20 (Figure 8). Furthermore, in the great apes, $P R R 20$ is arranged into a tandem array as seen in humans, with at least one complete orangutan (Pongo abelii) BAC clone (Accession Number AC206922) containing 17 copies of the gene arranged in tandem (Data not shown). Of the five complete human PRR20 monomers present in the human genome, no SNPs exist within the ORF between the different monomers.

According to the human genome sequence, the five complete monomers are arranged in tandem (Figure $7 \mathrm{~B})$. We sought to confirm the size of the array and investigate copy number variation in 11 unrelated individuals. Alleles for the PRR20 array ranged from 5 tandem copies to as many as 20 (Figure 7C) indicating that this is indeed a polymorphic macrosatellite.
Characterization of the ZAV macrosatellite array on human chromosome $9 q 32$

One other macrosatellite candidate identified in our search resides within a moderately gene rich region of human chromosome 9q32 (Figure 9A). The closest gene is ZFP37, a member of the KRAB zinc finger gene family that is located immediately adjacent to the array within $2 \mathrm{~kb}$ of the proximal edge and is transcribed away from the array. On the distal side the nearest annotated gene is $S L C 31 A 2$ which is $62 \mathrm{~kb}$ away from the edge of the array. Between the array and SLC $31 A 2$ is an inverted repeat that transcribes a non-coding RNA of unknown function. A similar inverted repeat is present upstream of the mouse $Z f p 37$ gene on chromosome $4 \mathrm{qB} 3$, but there is no evidence of the tandem array suggesting that this genomic feature is a more recent acquisition in humans (data not shown).

Each tandem repeat unit of the array is $5.3 \mathrm{~kb}$ and $60 \%$ GC. A little over $28 \%$ of each monomer is repeat masked due to the presence of simple microsatellite repeats, an LTR and regions of LINE homology. Two CGIs are found in each repeat unit, one spanning $1.4 \mathrm{~kb}$ and the other close to $700 \mathrm{bp}$. Therefore almost $40 \%$ of 


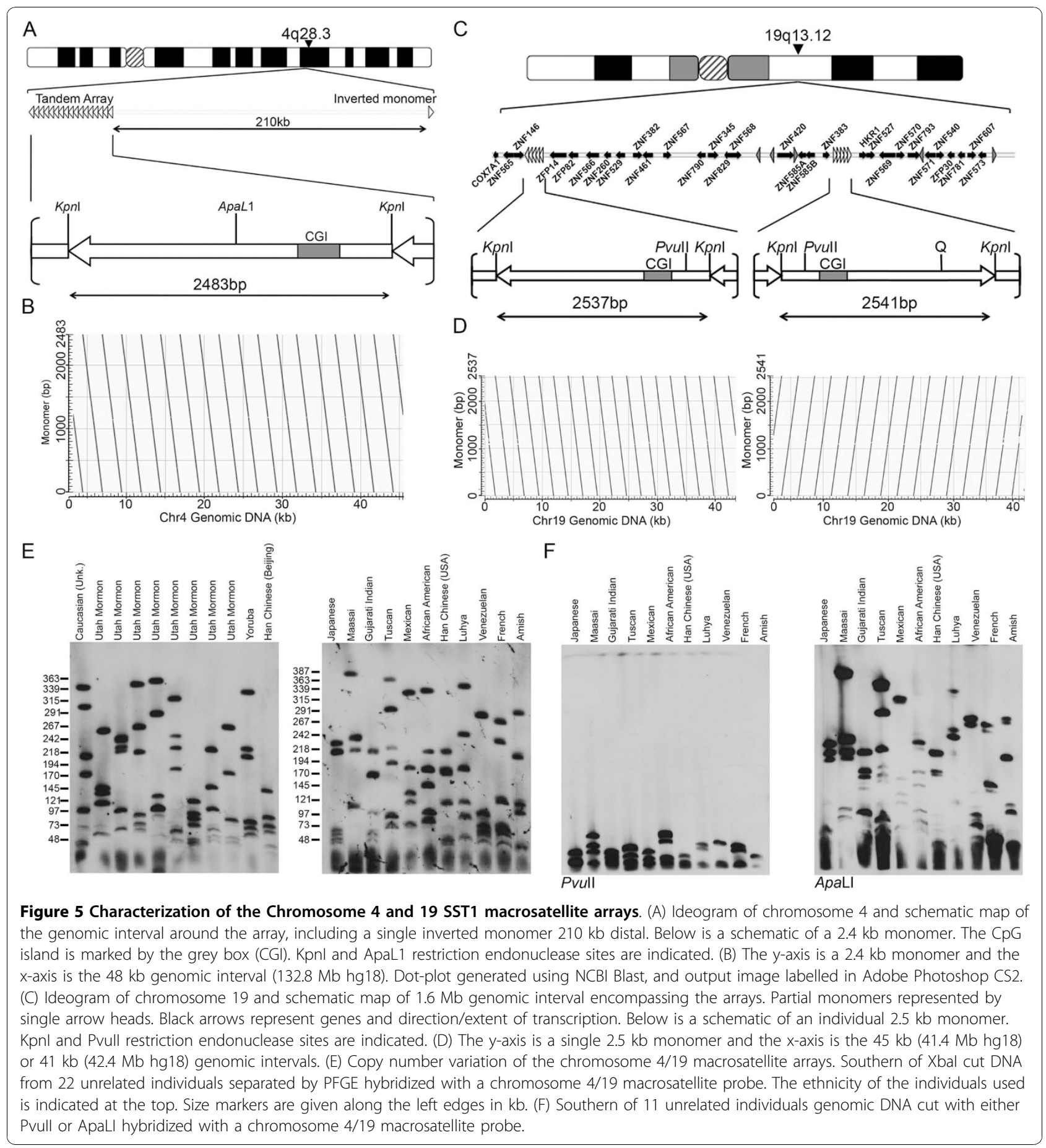

each monomer, accounting for most of the non-repeat masked region, is a characterized by a CGI. In the current build of the human genome, the array is annotated as 5 repeat units arranged in tandem (Figure 9B). As for the other arrays we examined 22 unrelated individuals to see if the array was polymorphic. Alleles for the array ranged from as small as $20 \mathrm{~kb}$ to $168 \mathrm{~kb}$ (Figure 9C) indicating that this is indeed a macrosatellite repeat with between 3-31 tandem repeat units and was termed the ZFP37-Associated VNTR (ZAV).

One EST aligned with the larger of the two CGIs. We designed primers to this region and looked to see if the array is expressed in any of the 20 human tissue cDNA samples. Clearly the ZAV array is expressed in fetal brain and testis, with weaker signals in whole brain, thymus, uterus and spinal cord (Figure 4, fourth row). 


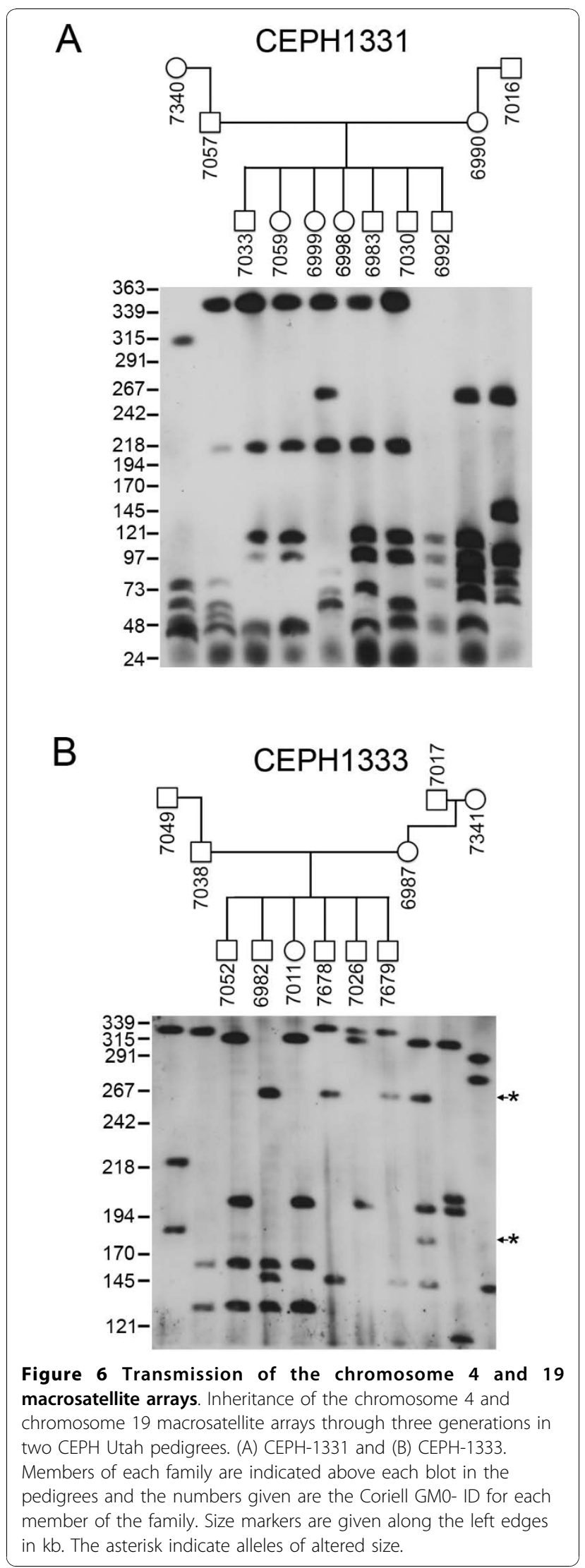

\section{Discussion}

Here we describe the organization, size variation and expression of four macrosatellite arrays in the human genome that is summarized in Table 2. Consistent with other macrosatellite arrays [3-6] alleles of each array show a wide range of tandem repeat unit copy number variation, with the chromosome 19 SST1 macrosatellite displaying alleles with the largest number of tandem repeat units described to date for a human macrosatellite. Also consistent with data for the RS447 macrosatellite [3] we present evidence of meiotic and mitotic instability for the SST1 and TAF11-Like arrays in a relatively small sample size. Of note, the chromosome $9 q 32$ ZAV macrosatellite described here and the RS447 array reside within common fragile sites in the human genome [34] and could potentially contribute to chromosome breaks and rearrangements frequently observed in tumor cells. Taken together, these data are consistent with the reported instability of macrosatellite sequences and further highlight their contribution as extreme forms of copy number variation in the human genome.

Among the macrosatellites described here, the SST1 array is the only one that is not chromosome specific, but has arrays of significant size $1 \mathrm{Mb}$ apart on 19q13.2 and an additional highly conserved array on chromosome 4q28.3 [2,33]. A similar situation is true for the FSHD-associated array D4Z4 that has near identical arrays on chromosomes 4q35 and 10q26. Exchange between the $4 \mathrm{q}$ and $10 \mathrm{q}$ D4Z4 arrays is common in the general population [35]. The subtelomeric location of the arrays results only in the expansion or contraction of an array as well as exchange of the limited DNA sequence from the distal edge of the array to the telomere. Should the chromosome 4 and 19 SST1 arrays recombine this would result in an extensive exchange. While we are aware of no such chromosome 4:19 translocations, it remains a distinct possibility that the two inverted chromosome 19q13 SST1 arrays could undergo intra-chromosomal non-allelic homologous recombination inverting the $1 \mathrm{Mb}$ interval between the arrays, especially given the extensive size and $>97 \%$ sequence identity between the two macrosatellite arrays.

An independent investigation using array comparative genome hybridization identified contracted alleles of the TAF11-Like array as a possible contributor to schizophrenia [36]. In one group of families, small alleles $(<21$ tandem repeat units) segregated with schizophrenia with only one unaffected sibling carrying a small sized allele. However, this association did not extend to other schizophrenia families and therefore linkage of small TAF11-Like arrays to the disease is not statistically significant. Interestingly, the extended analysis to other schizophrenia families made use of quantitative PCR 


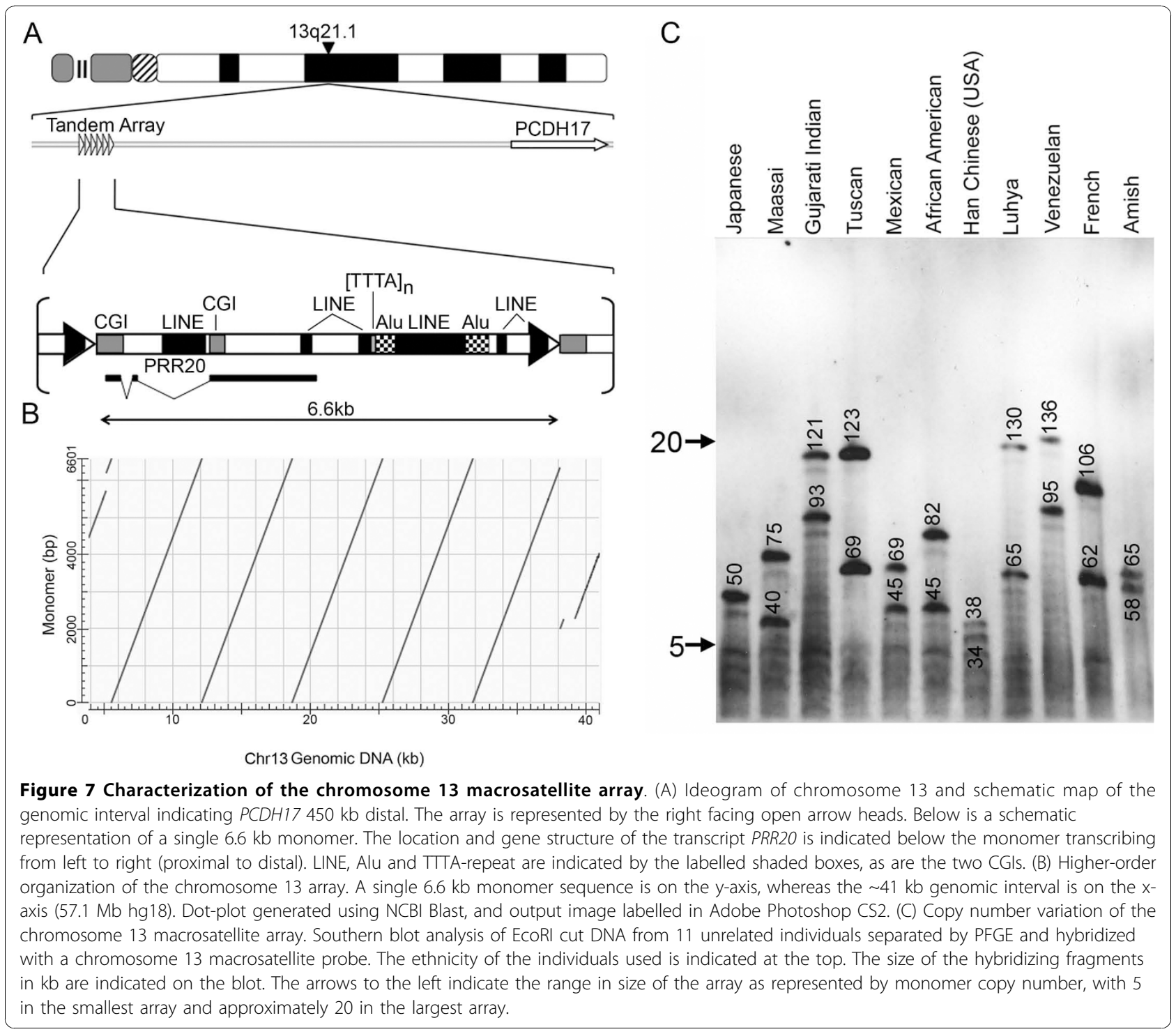

(qPCR) as opposed to PFGE to assess allele size. As the authors acknowledge, the results therefore represent the combined tandem repeat content of both chromosome 5 arrays, potentially masking small alleles. In the present study we also identified small alleles of the TAF11-Like array, with the smallest ( $\sim 10$ tandem repeat units) comparable in size to the pathogenic contracted D4Z4 alleles in FSHD [5]. For these particular individuals, who have alleles of 10 and 81 tandem repeats, qPCR would have indicated approximately 50 tandem repeat units in each chromosome 5 array. This highlights that despite numerous advances in genome research tools, PFGE remains the most effective and reliable means to measure allele size of tandem repeat DNA.

Expression analysis of the four macrosatellite described here revealed that all of the arrays are expressed at high levels in the testis and to a lesser extent in fetal brain and in adult brain (except PRR20). The notable exception is SST1 that is ubiquitously expressed in all tissues examined. Furthermore, expression was independent of a clear ORF as demonstrated by the SST1 and ZAV macrosatellites, although it remains a possibility that either has a short ORF with no homology to known proteins. Expression in the testis is a defining feature of the cancer/testis (CT) genes [37], many of which are arranged into tandem arrays $[38,39]$. Therefore, it is possible that the ZAV, PRR20 or TAF11-Like macrosatellites are novel members of the cancer/testis group, as some CT-genes are expressed in developing neurons as well as testis [40]. Regardless, the strong expression in testis indicates that these arrays are likely packaged into an alternate chromatin state in this organ, most likely in the germ cells, as is the case for some MAGE and GAGE CT genes [41]. 


\begin{tabular}{|c|c|c|}
\hline $\begin{array}{l}\text { Human } \\
\text { Chimp } \\
\text { Gorilla } \\
\text { Orangutan } \\
\text { Macaque }\end{array}$ & $\begin{array}{l}1 \\
1 \\
1 \\
1 \\
1\end{array}$ & 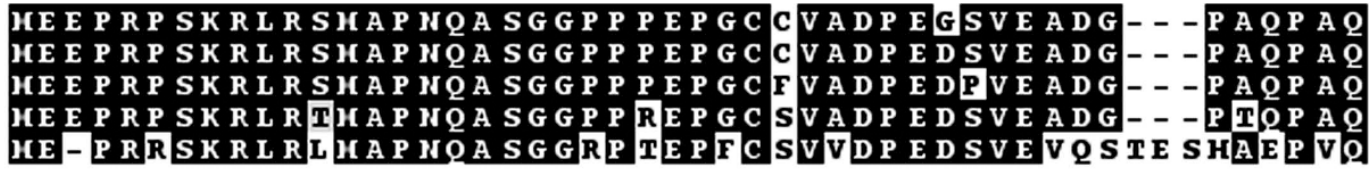 \\
\hline $\begin{array}{l}\text { Human } \\
\text { Chimp } \\
\text { Gorilla } \\
\text { Orangutan } \\
\text { Macaque }\end{array}$ & $\begin{array}{l}48 \\
48 \\
48 \\
48 \\
50\end{array}$ & 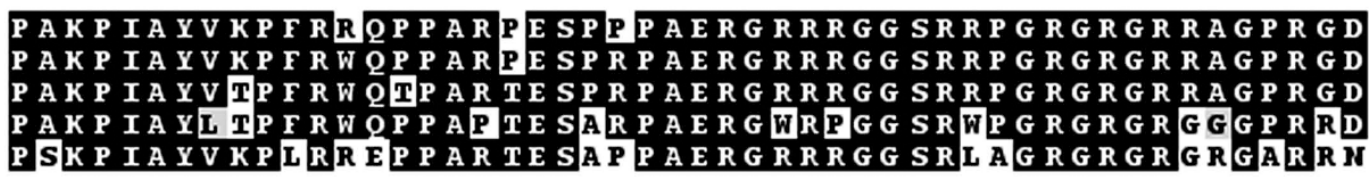 \\
\hline $\begin{array}{l}\text { Human } \\
\text { Chimp } \\
\text { Gorilla } \\
\text { Orangutan } \\
\text { Macaque }\end{array}$ & $\begin{array}{r}98 \\
98 \\
98 \\
98 \\
100\end{array}$ & 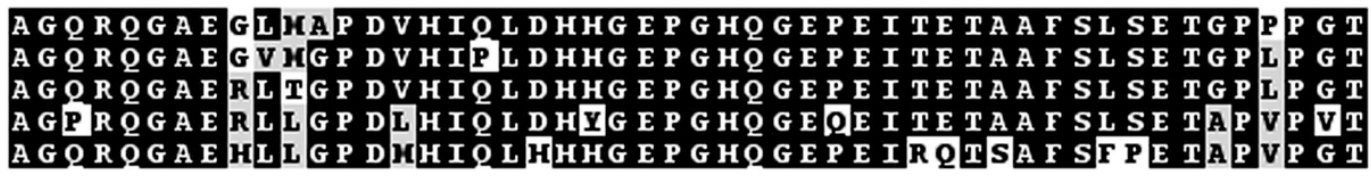 \\
\hline $\begin{array}{l}\text { Human } \\
\text { Chimp } \\
\text { Gorilla } \\
\text { Orangutan } \\
\text { Macaque }\end{array}$ & $\begin{array}{l}148 \\
148 \\
148 \\
148 \\
150\end{array}$ & 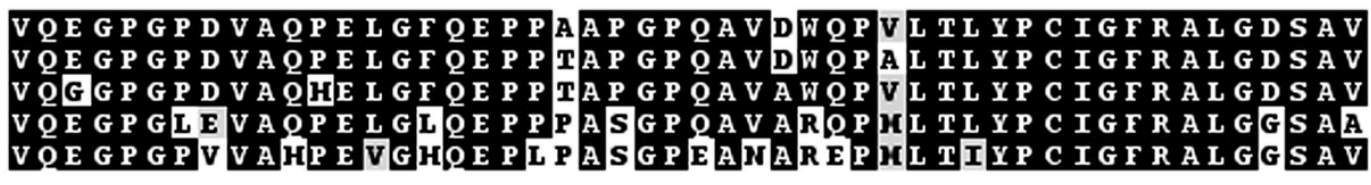 \\
\hline $\begin{array}{l}\text { Human } \\
\text { Chimp } \\
\text { Gorilla } \\
\text { Orangutan } \\
\text { Macaque }\end{array}$ & $\begin{array}{l}198 \\
198 \\
198 \\
198 \\
200\end{array}$ & 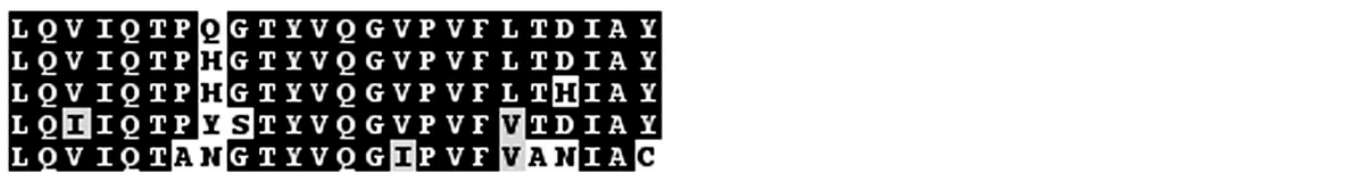 \\
\hline \multicolumn{3}{|c|}{$\begin{array}{l}\text { Figure } 8 \text { Conservation of PRR20 in primates. Alignment of the predicted amino-acid sequence of the PRR20 protein from great apes and } \\
\text { macaque. The primate is listed to the left, as is the amino-acid residue number. Identical amino-acids are highlighted in black, amino-acids with } \\
\text { similar properties are black letters shaded grey and divergent residues are black letters on a white background. Gaps in the alignment are } \\
\text { represented by dashes. Alignments were prepared using ClustalW2 http://www.ebi.ac.uk/Tools/clustalw2/index.html and the output used to } \\
\text { generate the shaded version shown using the Boxshade } 3.21 \text { server http://www.ch.embnet.org/software/BOX_form.html. Chimp sequence } \\
\text { obtained from Pan troglodytes genome assembly (CGSC 2.1/panTro2) using the UCSC genome browser http://genome.ucsc.edu/. Gorilla } \\
\text { sequence obtained from Gorilla gorilla genome assembly (gorGor3) using the Ensembl genome browser http://www.ensembl.org/index.html. } \\
\text { Orangutan sequence obtained from a complete Pongo abelii BAC clone (Accession Number AC206922). Macaque sequence obtained from } \\
\text { Macaca mulatta genome assembly (rheMac2) using the UCSC genome browser. }\end{array}$} \\
\hline
\end{tabular}

What influence variation in the number of copies of individual tandem repeat units has, if any, on flanking gene expression remains an important question to be addressed, despite the conflicting data regarding D4Z4 [11-19]. For some such as the chromosome 4 SST1 array or the PRR20 array on chromosome 13q21.1 any influence is likely negligible given that the nearest annotated genes are considerable physical distances away. The TAF11-Like array is also some distance from the distal BASP1 gene $(210 \mathrm{~kb})$ and therefore is also unlikely to exert any influence on its expression. However, this is making the assumption that influence is 2-dimensional and does not take into account where in 3-dimensional space the arrays are located relative to other genes. In contrast, the 9q32 ZAV array and SST1 arrays at 19q13.12 could conceivably directly influence flanking gene expression. The ZAV array is approximately $2 \mathrm{~kb}$ from the proximal ZFP37 gene is composed of GC rich tandem repeat units that each contain two extensive CGIs. Evidence supporting such a notion comes from the fact that the murine homolog $Z f p-37$ is expressed specifically in the brain and testis [42], mirroring the human array expression pattern. Therefore, it is tempting to posit that the array in humans is an extensive regulatory element of the ZFP37 gene. The location of the chromosome 19 SST1 arrays are intriguing due to the presence of the 29 zinc-finger genes that reside between and immediately proximal/distal of the two macrosatellites. Of the approximately 800 zinc-finger genes in the human genome, a disproportionate number reside on chromosome 19 , with most residing in one of 11 clusters [43]. This is not the only kruppel-type zinc finger cluster on chromosome 19 that is associated with tandem repeat DNA, as an extensive cluster at $19 \mathrm{p} 12$ is interspersed with blocks of $\beta$-satellite [44]. Kruppel-type zinc fingers are implicated in transcriptional regulation 
A
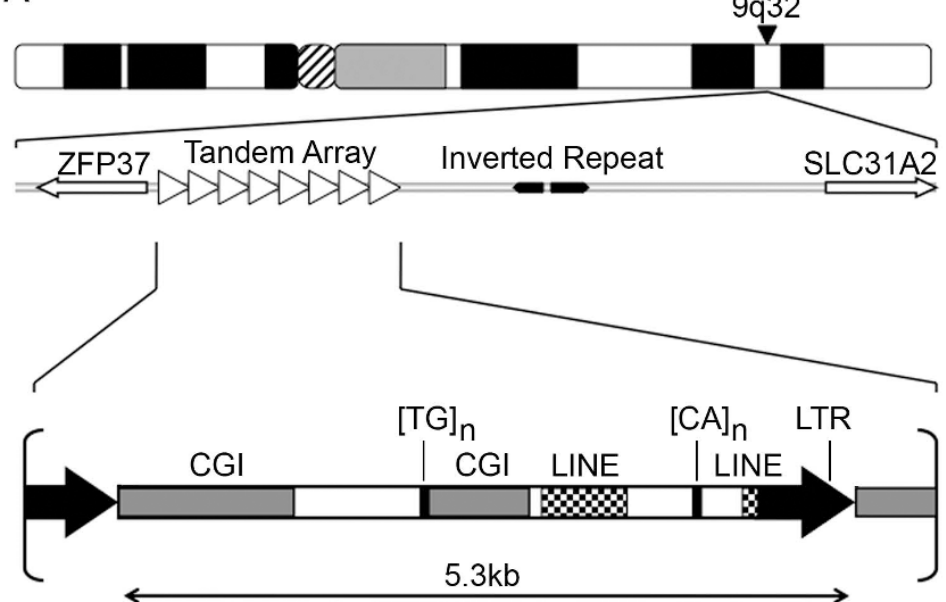

B

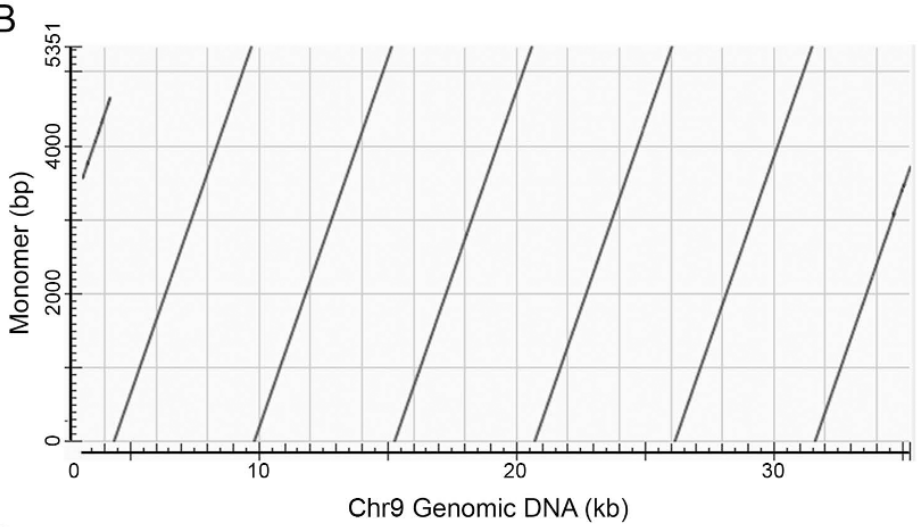

C
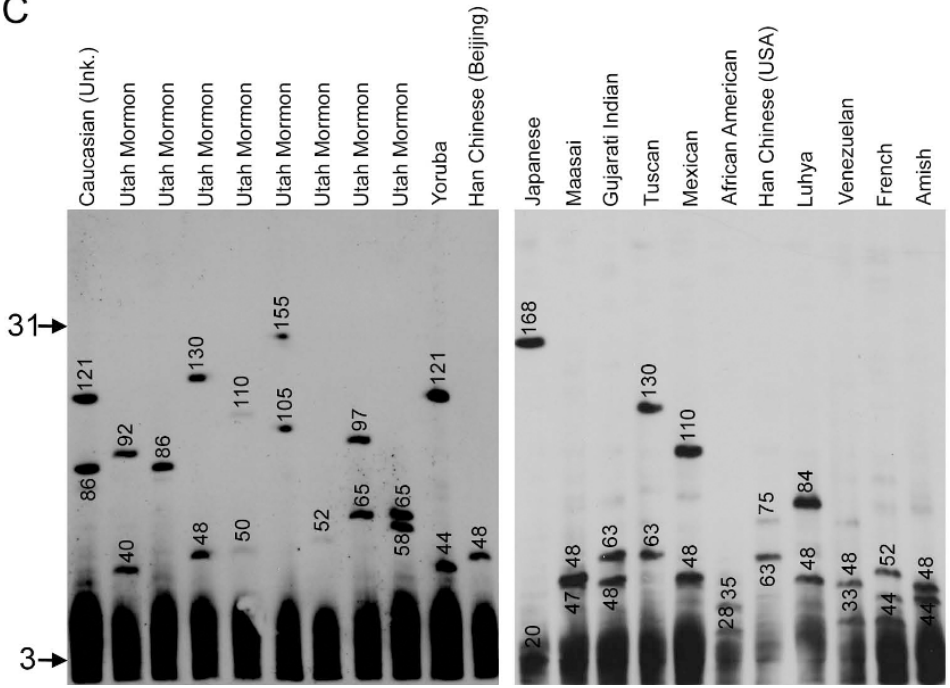

Figure 9 Characterization of the chromosome 9 ZAV macrosatellite array. (A) Ideogram of chromosome 9 and schematic map of the genomic interval. The array is represented by the right facing open arrow heads. Immediately proximal $(<2 \mathrm{~kb})$ is the ZFP37 gene. To the distal side of the array is a inverted repeat and the SLC31A2 gene (60 kb distal). Below is a schematic representation of a single $5.3 \mathrm{~kb}$ monomer. LINE \& LTR regions are highlighted as is the microsatellite repeats and the two CG1s. (B) Higher-order organization of the chromosome 9. A single 5.3 $\mathrm{kb}$ monomer sequence is on the $\mathrm{y}$-axis, whereas the $\sim 35 \mathrm{~kb}$ (114.8 Mb hg18).. Dot-plot generated using NCBI Blast, and output image labelled in Adobe Photoshop CS2. (C) Copy number variation of the chromosome 9 macrosatellite array. Southern of Xbal cut DNA from 22 unrelated individuals separated by PFGE and hybridized with a chromosome 9 macrosatellite probe. The ethnicity of the individuals used is indicated at the top. The size of the hybridizing fragments in $\mathrm{kb}$ are indicated on the blot. The arrows to the left indicate the range in size of the array as represented by monomer copy number, with 3 in the smallest array and approximately 31 in the largest array. 
Table 2 Macrosatellite Summary

\begin{tabular}{|c|c|c|c|c|}
\hline Array & TAF11-Like & $\begin{array}{l}\text { SST1 (Chr4 } \\
\& 19)\end{array}$ & PRR20 & ZAV \\
\hline Monomer size & $3.4 \mathrm{~kb}$ & $2.4-2.5 \mathrm{~kb}$ & $6.6 \mathrm{~kb}$ & $5.3 \mathrm{~kb}$ \\
\hline GC Content & $50 \%$ & $64 \%$ & $50 \%$ & $60 \%$ \\
\hline $\begin{array}{l}\text { Number of unrelated } \\
\text { array alleles }\end{array}$ & 54 & 134 & 20 & 41 \\
\hline $\begin{array}{l}\text { Average array allele } \\
\text { size (Median) }\end{array}$ & 178 kb (178 kb) & $\begin{array}{l}161 \mathrm{~kb}(127 \\
\mathrm{kb})\end{array}$ & 76 kb (67 kb) & 71 kb (58 kb) \\
\hline Range allele size & $34-335 \mathrm{~kb}$ & $35-387 \mathrm{~kb}$ & $34-136 \mathrm{~kb}$ & $20-168 \mathrm{~kb}$ \\
\hline $\begin{array}{l}\text { Inferred monomer } \\
\text { copy number }\end{array}$ & $10-98$ & $14-154$ & $5-20$ & $3-31$ \\
\hline Expression (weaker) & $\begin{array}{l}\text { Testis Fetal Brain Whole Brain } \\
\text { (Fetal Liver \& Prostate) }\end{array}$ & $\begin{array}{l}\text { All tissues } \\
\text { examined }\end{array}$ & $\begin{array}{l}\text { Testis (Cerebellum, Fetal Brain, } \\
\text { Prostate \& Thymus) }\end{array}$ & $\begin{array}{l}\text { Testis Fetal Brain (Whole Brain, Thymus, } \\
\text { Uterus \& Spinal Cord) }\end{array}$ \\
\hline ORF & TAF11-Like & - & PRR20 & - \\
\hline
\end{tabular}

Table summarizing features of the macrosatellite arrays

of many crucial processes from development to control of the cell cycle to pluripotency [45]. Despite their close proximity, zinc finger genes within a cluster are differentially expressed [46] and therefore intricate modes of regulation must be required to tightly regulate the expression of cluster members. We propose that the SST1 array at $19 \mathrm{q} 13.12$ has a role in the regulation of the surrounding zinc finger gene cluster.

\section{Conclusions}

The wealth of information made available from the human genome project has provided an invaluable tool to assist in the identification and characterization of complex repetitive DNA elements such as the macrosatellites. Our results more than double the number of characterized macrosatellite arrays in the human genome and further highlight our lack of understanding as to the role of these unusual sequences in genome biology despite their direct relevance to disease. We anticipate that further characterization of these arrays will reveal the functional significance of macrosatellites arrays, explaining why they are retained in our genome.

\section{Methods}

\section{Cell lines}

Lymphoblastoid cell lines of CEPH family members and the individuals used in the variation panels were obtained from the Coriell Institute for Medical Research http://www.coriell.org/. Cells were maintained according to Coriell recommendations. Culture media (RPMI), fetal bovine serum and supplements were all obtained from Invitrogen corp.

\section{Plug preparation}

Approximately $4 \times 10^{7}$ cells were resuspended in $1 \mathrm{ml}$ of L-buffer (100 mM EDTA [8.0], $10 \mathrm{mM}$ Tris- $\mathrm{HCl}$ [8.0], $20 \mathrm{mM} \mathrm{NaCl}$ ), before mixing $1: 1$ with $1.0 \%(\mathrm{w} / \mathrm{v})$ molten low-melt agarose (Biorad). The cell mixture was transferred to plug moulds (Biorad) with $\sim 80 \mathrm{ul}$ of the cell suspension per plug (approximately $1.6 \times 10^{6}$ cells/ plug). Plugs were allowed to set at $4^{\circ} \mathrm{C}$ for 10 minutes before transfer to 10 volumes of L-buffer containing $1 \%$ (w/v) sarkosyl and $1 \mathrm{mg} / \mathrm{ml}$ Proteinase-K (Roche) and incubating overnight at $50^{\circ} \mathrm{C}$. Plugs were rinsed with water before three washes of one hour each with 50 volumes of $\mathrm{TE}$ [8.0]. Plugs were incubated at $50^{\circ} \mathrm{C}$ for 30 minutes in 10 volumes of TE [8.0] supplemented with $80 \mathrm{ug} / \mathrm{ml}$ PMSF (Roche). Plugs were rinsed once more with water before three additional hour-long washes in 50 volumes of TE [8.0] at room temperature before storage at $4^{\circ} \mathrm{C}$.

\section{Pulsed field gel electrophoresis}

Agarose embedded DNA was digested with the restriction enzymes given in the legend for the appropriate data figures. All enzymes were obtained from NEB. Each plug was first equilibrated in $300 \mathrm{ul}$ of $1 \times$ digest buffer at room temperature for 20 minutes, before replacement of buffer with $100 \mathrm{ul}$ of $1 \times$ digest buffer containing 200 units of restriction enzyme. Digests were performed overnight at $37^{\circ} \mathrm{C}$. Plugs were loaded onto a $1.0 \%$ agarose gel prepared using pulsed field certified agarose (Biorad) in $0.5 \times \mathrm{TBE}$. DNA was separated at $14^{\circ} \mathrm{C}$ in $0.5 \times \mathrm{TBE}$ according to the time and conditions determined by the auto algorithm function of the CHEF Mapper (Biorad). Markers were loaded in the outer lanes (NEB, MidRange PFG Markers I and II).

\section{Southern blotting \& hybridization}

At the end of the PFGE run, the gel was rinsed with water before staining with ethidium bromide $(1 \mathrm{ug} / \mathrm{ml})$ at room temperature for 30 minutes. The gel was washed twice with water for 15 minutes each and an image captured. The gel was then treated with $0.25 \mathrm{M}$ 
$\mathrm{HCl}$ for 15 minutes before denaturing for 30 minutes $(1.5 \mathrm{M} \mathrm{NaCl}, 0.5 \mathrm{M} \mathrm{NaOH})$. DNA was transferred to Hybond-N+ (GE Healthcare) overnight by standard Southern blotting [47]. The membrane was rinsed with $2 \times \mathrm{SSC}$ before baking at $120^{\circ} \mathrm{C}$ for 30 minutes.

Macrosatellite specific probes were prepared by PCR amplification using primers listed in table 1 . The PCR products were cleaned (Qiagen) before labelling with DIG-11-dUTP by random priming (Roche). The probes were tested for specificity and detection of the anticipated DNA fragment size on a Southern blot of EcoRI digested total genomic DNA.

Hybridization was performed overnight at $60^{\circ} \mathrm{C}$ using Expresshyb (Clontech). Blots were washed the following day at $60^{\circ} \mathrm{C}$ using two 8 minute washes in $2 \times \mathrm{SSC}$, $0.1 \%$ SDS followed by one wash of 8 minutes in $0.2 \times$ SSC, $0.1 \%$ SDS. The probe was detected using anti-DIGalkaline phosphatase, blocking, wash and detection buffers according to the manufacturers instructions (Roche). Signals were detected by exposure to photographic film (Kodak).

\section{Reverse Transcription PCR}

Human tissue total RNA was obtained from Clontech (636643). Residual genomic DNA was removed by pretreating the RNA with DNaseI (Invitrogen) for 20 minutes at room temperature, before heat inactivating the DNaseI at $70^{\circ} \mathrm{C}$ in the presence of $2.5 \mathrm{mM}$ EDTA for 15 minutes. Complementary DNA was prepared using $1 \mathrm{ug}$ of total RNA with or without MMLV reverse transcriptase (Invitrogen) according to the manufacturers instructions.

cDNA was amplified using Taq polymerase (NEB) with the following cycle: $95^{\circ} \mathrm{C}$ for 2 minutes, followed by 35 cycles of $95^{\circ} \mathrm{C} 20$ seconds, $58^{\circ} \mathrm{C} 20$ seconds, $72^{\circ} \mathrm{C}$ 30 seconds. Primers used for amplification and size of anticipated product are listed in Table 1.

\section{Acknowledgements}

This work was supported in part by a grant from the National Institutes of Health (GM073120, B.P.C).

\section{Author details}

'Department of Biological Sciences, Florida State University, King Life Science Building, Tallahassee, FL 32306-4295, USA. ${ }^{2}$ GGSP Sequencing Core Facility, Duke University, Durham, NC 27708, USA.

\section{Authors' contributions \\ BPC conceived of the study, analyzed and interpreted data, performed experiments, and wrote the manuscript. DCT, GA, SM and BPC carried out experiments. All authors have read and approved the final manuscript.}

\section{Competing interests}

The authors declare they have no competing interests.

Received: 8 October 2010 Accepted: 15 November 2010 Published: 15 November 2010
References

1. Lander ES, Linton LM, Birren B, Nusbaum C, Zody MC, Baldwin J, Devon K, Dewar K, Doyle M, FitzHugh W, Funke R, Gage D, Harris K, Heaford A, Howland J, Kann L, Lehoczky J, LeVine R, McEwann P, McKernan K, Meldrim J, Mesirov JP, Miranda C, Morris W, Naylor J, Raymond C, Rosetti M, Santos $R$, Sheridan A, Sougnex $C$, et al: Initial sequencing and analysis of the human genome. Nature 2001, 409:860-921.

2. Warburton PE, Hasson D, Guillem F, Lescale C, Jin X, Abrusan G: Analysis of the largest tandemly repeated DNA families in the human genome. BMC Genomics 2008, 9:533.

3. Okada T, Gondo Y, Goto J, Kanazawa I, Hadano S, Ikeda JE: Unstable transmission of the RS447 human megasatellite tandem repetitive sequence that contains the USP17 deubiquitinating enzyme gene. Hum Genet 2002, 110:302-313.

4. van Deutekom JC, Wijmenga C, van Tienhoven EA, Gruter AM, Hewitt JE, Padberg GW, van Ommen GJ, Hofker MH, Frants RR: FSHD associated DNA rearrangements are due to deletions of integral copies of a $3.2 \mathrm{~kb}$ tandemly repeated unit. Hum Mol Genet 1993, 2:2037-2042.

5. Wijmenga C, Hewitt JE, Sandkuijl LA, Clark LN, Wright TJ, Dauwerse HG, Gruter AM, Hofker MH, Moerer P, Williamson R, van Ommen GJ,

Padberg GW, Frants RR: Chromosome 4q DNA rearrangements associated with facioscapulohumeral muscular dystrophy. Nat Genet 1992, 2:26-30.

6. Giacalone J, Friedes J, Francke U: A novel GC-rich human macrosatellite VNTR in Xq24 is differentially methylated on active and inactive $X$ chromosomes. Nat Genet 1992, 1:137-143.

7. Rudd MK, Wray GA, Willard HF: The evolutionary dynamics of alphasatellite. Genome Res 2006, 16:88-96.

8. Moyzis RK, Buckingham JM, Cram LS, Dani M, Deaven LL, Jones MD, Meyne J, Ratliff RL, Wu JR: A highly conserved repetitive DNA sequence, (TTAGGG)n, present at the telomeres of human chromosomes. Proc Natl Acad Sci USA 1988, 85:6622-6626.

9. de Greef JC, Frants RR, van der Maarel SM: Epigenetic mechanisms of facioscapulohumeral muscular dystrophy. Mutat Res 2008, 647:94-102.

10. Hewitt JE, Lyle R, Clark LN, Valleley EM, Wright TJ, Wijmenga C, van Deutekom JC, Francis F, Sharpe PT, Hofker M, Frants RR, Williamson R: Analysis of the tandem repeat locus D4Z4 associated with facioscapulohumeral muscular dystrophy. Hum Mol Genet 1994, 3:1287-1295.

11. Bodega B, Ramirez GD, Grasser F, Cheli S, Brunelli S, Mora M, Meneveri R, Marozzi A, Mueller S, Battaglioli E, Ginelli E: Remodeling of the chromatin structure of the facioscapulohumeral muscular dystrophy (FSHD) locus and upregulation of FSHD-related gene 1 (FRG1) expression during human myogenic differentiation. BMC Biol 2009, 7:41.

12. Gabellini D, Green MR, Tupler R: Inappropriate gene activation in FSHD: a repressor complex binds a chromosomal repeat deleted in dystrophic muscle. Cell 2002, 110:339-348.

13. Klooster R, Straasheijm K, Shah B, Sowden J, Frants R, Thornton C, Tawil R, van der Maarel S: Comprehensive expression analysis of FSHD candidate genes at the mRNA and protein level. Eur J Hum Genet 2009, 17:1615-1624.

14. Rijkers T, Deidda G, van Koningsbruggen $S$, van Geel M, Lemmers RJ, van Deutekom JC, Figlewicz D, Hewitt JE, Padberg GW, Frants RR, van der Maarel SM: FRG2, an FSHD candidate gene, is transcriptionally upregulated in differentiating primary myoblast cultures of FSHD patients. J Med Genet 2004, 41:826-836.

15. Celegato B, Capitanio D, Pescatori M, Romualdi C, Pacchioni B, Cagnin S, Vigano A, Colantoni L, Begum S, Ricci E, Wait R, Lanfranchi G, Gelfi C: Parallel protein and transcript profiles of FSHD patient muscles correlate to the D4Z4 arrangement and reveal a common impairment of slow to fast fibre differentiation and a general deregulation of MyoD-dependent genes. Proteomics 2006, 6:5303-5321.

16. Jiang $G$, Yang $F$, van Overveld $P G$, Vedanarayanan $V$, van der Maarel $S$, Ehrlich M: Testing the position-effect variegation hypothesis for facioscapulohumeral muscular dystrophy by analysis of histone modification and gene expression in subtelomeric 4q. Hum Mol Genet 2003, 12:2909-2921.

17. Masny PS, Chan OY, de Greef JC, Bengtsson U, Ehrlich M, Tawil R, Lock LF, Hewitt JE, Stocksdale J, Martin JH, van der Maarel SM, Winokur ST: Analysis of allele-specific RNA transcription in FSHD by RNA-DNA FISH in single myonuclei. Eur J Hum Genet 2010, 18:448-456. 
18. Osborne RJ, Welle S, Venance SL, Thornton CA, Tawil R: Expression profile of FSHD supports a link between retinal vasculopathy and muscular dystrophy. Neurology 2007, 68:569-577.

19. Winokur ST, Chen YW, Masny PS, Martin JH, Ehmsen JT, Tapscott SJ, van der Maarel SM, Hayashi Y, Flanigan KM: Expression profiling of FSHD muscle supports a defect in specific stages of myogenic differentiation. Hum Mol Genet 2003, 12:2895-2907.

20. Saitoh Y, Miyamoto N, Okada T, Gondo Y, Showguchi-Miyata J, Hadano S, Ikeda JE: The RS447 human megasatellite tandem repetitive sequence encodes a novel deubiquitinating enzyme with a functional promoter. Genomics 2000, 67:291-300

21. Dixit M, Ansseau E, Tassin A, Winokur S, Shi R, Qian H, Sauvage S, Matteotti C, van Acker AM, Leo O, Figlewicz D, Barro M, LaoudjChenivesse D, Belayew A, Coppee F, Chen YW: DUX4, a candidate gene of facioscapulohumeral muscular dystrophy, encodes a transcriptional activator of PITX1. Proc Natl Acad Sci USA 2007, 104:18157-18162.

22. Bosnakovski D, Daughters RS, Xu Z, Slack JM, Kyba M: Biphasic myopathic phenotype of mouse DUX, an ORF within conserved FSHD-related repeats. PLoS One 2009, 4:e7003.

23. Snider $L$, Asawachaicharn A, Tyler AE, Geng LN, Petek LM, Maves $L$, Miller DG, Lemmers RJ, Winokur ST, Tawil R, van der Maarel SM Fillippova GN, Tapscott SJ: RNA Transcripts, miRNA-sized Fragments, and Proteins Produced from D4Z4 Units: New Candidates for the Pathophysiology of Facioscapulohumeral Dystrophy. Hum Mol Genet 2009.

24. Lemmers RJ, van der Vliet PJ, Klooster R, Sacconi S, Camano P, Dauwerse JG, Snider L, Straasheijm KR, Jan van Ommen G, Padberg GW Miller DG, Tapscott SJ, Tawil R, Frants RR, van der Maarel SM: A Unifying Genetic Model for Facioscapulohumeral Muscular Dystrophy. Science 2010.

25. Chadwick BP: DXZ4 chromatin adopts an opposing conformation to that of the surrounding chromosome and acquires a novel inactive X-specific role involving CTCF and antisense transcripts. Genome Res 2008, 18:1259-1269.

26. Payer B, Lee JT: X Chromosome Dosage Compensation: How Mammals Keep the Balance. Annu Rev Genet 2008.

27. Chadwick BP, Willard HF: Cell cycle-dependent localization of macroH2A in chromatin of the inactive X chromosome. J Cell Biol 2002. 157:1113-1123.

28. Filippova GN: Genetics and epigenetics of the multifunctional protein CTCF. Curr Top Dev Biol 2008, 80:337-360.

29. Chadwick BP: Macrosatellite epigenetics: the two faces of DXZ4 and D4Z4. Chromosoma 2009, 118:675-681.

30. Ottaviani A, Rival-Gervier S, Boussouar A, Foerster AM, Rondier D, Sacconi S, Desnuelle C, Gilson E, Magdinier F: The D4Z4 macrosatellite repeat acts as a CTCF and A-type lamins-dependent insulator in facio-scapulo-humeral dystrophy. PLoS Genet 2009, 5:e1000394.

31. Ide S, Miyazaki T, Maki H, Kobayashi T: Abundance of ribosomal RNA gene copies maintains genome integrity. Science 2010, 327:693-696.

32. Bailey JA, Yavor AM, Massa HF, Trask BJ, Eichler EE: Segmental duplications: organization and impact within the current human genome project assembly. Genome Res 2001, 11:1005-1017.

33. Epstein ND, Karlsson S, O'Brien S, Modi W, Moulton A, Nienhuis AW: A new moderately repetitive DNA sequence family of novel organization. Nucleic Acids Res 1987, 15:2327-2341.

34. Durkin SG, Glover TW: Chromosome fragile sites. Annu Rev Genet 2007, 41:169-192

35. van Deutekom JC, Bakker E, Lemmers RJ, van der Wielen MJ, Bik E, Hofker MH, Padberg GW, Frants RR: Evidence for subtelomeric exchange of $3.3 \mathrm{~kb}$ tandemly repeated units between chromosomes $4 \mathrm{q} 35$ and 10q26: implications for genetic counselling and etiology of FSHD1. Hum Mol Genet 1996, 5:1997-2003.

36. Bruce HA, Sachs N, Rudnicki DD, Lin SG, Willour VL, Cowell JK, Conroy J, McQuaid DE, Rossi M, Gaile DP, Norwak NJ, Holmes SE, Sklar P, Ross CA, Delisi LE, Margolis RL: Long tandem repeats as a form of genomic copy number variation: structure and length polymorphism of a chromosome $5 p$ repeat in control and schizophrenia populations. Psychiatr Genet 2009, 19:64-71.

37. Scanlan MJ, Gordon CM, Williamson B, Lee SY, Chen YT, Stockert E, Jungbluth A, Ritter G, Jager D, Jager E, Knuth A, Old LJ: Identification of cancer/testis genes by database mining and mRNA expression analysis. Int J Cancer 2002, 98:485-492.

38. Chen YT, Iseli C, Venditti CA, Old L, Simpson AJ, Jongeneel CV: Identification of a new cancer/testis gene family, CT47, among expressed multicopy genes on the human X chromosome. Genes Chromosomes Cancer 2006, 45:392-400.

39. Gjerstorff MF, Ditzel HJ: An overview of the GAGE cancer/testis antigen family with the inclusion of newly identified members. Tissue Antigens 2008, 71:187-192.

40. Gjerstorff MF, Harkness L, Kassem M, Frandsen U, Nielsen O, Lutterodt M, Mollgard K, Ditzel HJ: Distinct GAGE and MAGE-A expression during early human development indicate specific roles in lineage differentiation. Hum Reprod 2008, 23:2194-2201.

41. Gjerstorff MF, Kock K, Nielsen O, Ditzel HJ: MAGE-A1, GAGE and NY-ESO-1 cancer/testis antigen expression during human gonadal development. Hum Reprod 2007, 22:953-960.

42. Mazarakis N, Michalovich D, Karis A, Grosveld F, Galjart N: Zfp-37 is a member of the KRAB zinc finger gene family and is expressed in neurons of the developing and adult CNS. Genomics 1996, 33:247-257.

43. Grimwood J, Gordon LA, Olsen A, Terry A, Schmutz J, Lamerdin J, Hellsten U, Goodstein D, Couronne O, Tran-Gyamfi M, Aerts A, Altherr M, Ashworth L, Bajorek E, Black S, Branscomb E, Caenepeel S, Carrano A, Caolie C, Chan YM, Chritensen M, Cleland CA, Copeland A, Dalin E, Dehal P, Denys M, Detter JC, Escobar J, Flowers D, Fotopulos D, et al: The DNA sequence and biology of human chromosome 19. Nature 2004, 428:529-535.

44. Eichler EE, Hoffman SM, Adamson AA, Gordon LA, McCready P, Lamerdin JE, Mohrenweiser HW: Complex beta-satellite repeat structures and the expansion of the zinc finger gene cluster in 19p12. Genome Res 1998, 8:791-808.

45. Swamynathan SK: Kruppel-like factors: three fingers in control. Hum Genomics 2010, 4:263-270.

46. Shannon M, Hamilton AT, Gordon L, Branscomb E, Stubbs L: Differential expansion of zinc-finger transcription factor loci in homologous human and mouse gene clusters. Genome Res 2003, 13:1097-1110.

47. Sambrook J, Fritsch EF, Maniatis T: Molecular Cloning: A laboratory manual. Second edition. Cold Spring Harbor, NY: Cold Spring Harbor Laboratory Press; 1989

doi:10.1186/1471-2164-11-632

Cite this article as: Tremblay et al:: Expression, tandem repeat copy number variation and stability of four macrosatellite arrays in the human genome. BMC Genomics 2010 11:632.

\section{Submit your next manuscript to BioMed Central and take full advantage of:}

- Convenient online submission

- Thorough peer review

- No space constraints or color figure charges

- Immediate publication on acceptance

- Inclusion in PubMed, CAS, Scopus and Google Scholar

- Research which is freely available for redistribution 